\title{
Early intervention services for psychosis in Ireland: are we there yet?
}

\author{
P. Power ${ }^{1,2, *}$ \\ ${ }^{1}$ Young Adult Service, St. Patrick's Mental Health Services, Dublin, Ireland \\ ${ }^{2}$ Department of Psychiatry, Trinity College Dublin, Dublin, Ireland
}

\begin{abstract}
Early intervention in psychosis (EIP) services are now a priority for Ireland's Health Service Executive (HSE). A Model of Care for EIP services has been completed after wide consultation. It has just been launched by the Minister for Mental Health and the aim now is to roll out EIP services throughout the country. The Model of Care outlines the rational, configuration, resources, governance, and quality assurance required to operate EIP services. Two models are recommended. The first is a Hub \& Spoke service model for rural and smaller urban areas. The second is a Stand-Alone service model for large urban and metropolitan areas. Introducing EIP services is going to be a challenge but there are plenty of good examples overseas. They have been shown to greatly enhance local services' ability to meet the needs of people developing psychotic disorders. They bring with them better outcomes, service satisfaction and cost savings.
\end{abstract}

Received 12 June 2019; Revised 10 September 2019; Accepted 22 September 2019

Key words: Early detection, early intervention in psychosis, Hub \& Spoke, Ireland, model of care, service models, stand-alone, ultra-high risk of psychosis.

\section{Introduction}

This special edition of the Irish Journal of Psychological Medicine is partially devoted to reviews and studies of early intervention in psychosis (EIP). It highlights some of the important research being undertaken in Ireland and puts Irish research in EIP firmly in the international arena. This comes at a pivotal time for Irish mental health services because we are now on the cusp of joining this international movement by rolling out our own EIP services nationally. EIP services have a proven track record of raising the standard of care and treatment, improving outcomes, reducing suffering, limiting the burden of care and reducing costs (Fusar-Poli et al. 2017; Correll et al. 2018; Aceituno et al. 2019). EIP has injected hope into a previously pessimistic view of psychosis (Goldner-Vukov et al. 2007; McGorry, 2015). It is backed up by high-quality research and evaluation, spurring an exponential growth in publications in this area over the past 20 years (McGorry, 2015). Alongside this are expanding worldwide networks and increasing membership of organisations such as the International Early Psychosis Association (Addington, 2012).

EIP has become widely accepted as best practice in the treatment of conditions such as schizophrenia (NICE, 2013, 2014). It is one of the major milestones in mental health care for those with psychosis over

*Address for correspondence: P. Power, Young Adult Service, St Patrick's University Hospital, James St. Dublin 8, Ireland. (Email: ppower@stpatsmail.com) the last 50 years following on from the introduction of antipsychotics, the closing down of asylums and the evolution of community mental health care. EIP borrows from similar approaches in medicine, education and social services. The approach is now being adopted into other areas of psychiatry such as youth mental health (McGorry \& Mei, 2018) and old age psychiatry (Byrne \& Rosen, 2014).

\section{The history of EIP services}

As a movement, EIP began nearly three decades ago with 'beacon' services such as the Early Psychosis Prevention and Intervention Centre in Melbourne Australia (1992), the Birmingham EIP service (1994), the Prevention and Early Intervention in Psychosis Programme in London, Ontario (1996), the Treatment and Intervention in Psychosis Study programme in Norway (1997), the Recognition and Prevention programme in New York (1998) and the Lambeth Early Onset service (2000) in London (Omer et al. 2010). In the last two decades, hundreds of EIP services have been rolled out across England, Canada, Australia, New Zealand, Denmark, parts of the Italy and USA, as well as many other individual examples in Europe, Iceland, South America, Mexico, Scandinavia, Singapore, Hong Kong, South Korea and Japan (Edwards \& McGorry, 2002; McGorry et al. 2008; Cocchi et al. 2015; McDaid et al. 2016; Csilag et al. 2018; Niendam et al. 2019). By 2014 in England, 150 EIP teams were up and running in the National 
Health Service (McDaid et al. 2016). Now, in 2019, the go-ahead has been given by the National Clinical Programme (NCP) to start funding and setting up these services across the Republic of Ireland (HSE National Clinical Programme, 2019 ).

Ireland's first EIP service, DETECT, was set up in 2005 in south county Dublin by the late Prof. Eadbhard O'Callaghan (Omer et al. 2010) with a focus on early detection and access into services. A second EIP service, Cavan/Monaghan Overcoming Psychosis Early (COPE), opened in the more rural setting of Cavan/Monaghan from a modified community rehabilitation team (Nkire et al. 2015). Both services were supported by grants and high-quality research initiatives. Despite the keen interest in EIP elsewhere in Ireland, few other EIP services have fully materialised - constrained by lack of funding and resources, for example, North Lee in Cork (Lalevic et al. 2019). It's only now, with Health Service Executive (HSE) funding, are well resourced EIP 'demonstration sites' starting up (www.hse.ie).

\section{The model of care for EIP services}

National planning for EIP services in Ireland dates back to 2010 following the formation of the HSE NCP for Mental Health. EIP was identified as one of its top three priorities (the other two were Eating Disorders and Deliberate Self Harm). A Programme Manager, Ms Rhona Jennings, was appointed and a multidisciplinary working group was formed with national representatives from health professional bodies and service users. The working group was strongly influenced by the pioneering work of DETECT. They produced an initial draft plan of a Clinical Programme for EIP (EIP Working Group 2012, unpublished) but in a climate of economic recession and cutbacks it was not to progress further.

Then in 2013, the HSE NCP and the College of Psychiatrists of Ireland (CPI) committed to jointly develop a Model of Care (MoC) for EIP services with the aim of rolling out these services nationally (www. hse.ie). A National Clinical Lead in EIP, Dr Katherine Brown, was appointed. Working Groups were convened and after much consultation (including input from international leaders in the field), an EIP MoC was drafted, redrafted and finally agreed upon in 2018 by the NCP EIP National Working Group, the CPI EIP Clinical Advisory Group (CAG), HSE Heads of Departments, Service User representatives, the CPI's Faculties and Council. In April 2019, the MoC was approved by Dr Colm Henry, Chief Clinical Officer HSE, and then officially launched by the Minister for Mental Health and Older People, Jim Daly, on 12 June 2019.
The aim of the NCP's EIP MoC (www.hse.ie/eng/ about/who/cspd/ncps/mental-health/psychosis / resources /) is to provide a framework for the establishment of EIP services across the country so that anyone who develops or is at 'Ultra-High Risk' (UHR) of developing a first episode of psychosis (FEP) will have access to these new services. Currently the new EIP services are limited to those aged 14-64 and do not yet include specialist services such as Intellectual Disability or Forensic Psychiatry as there is no evidence base as yet to show which EIP service model best suits these specialties. Indeed, most of the evidence base for EIP service models comes from youth-oriented EIP services (McDaid et al. 2016) and uncertainty remains about which model best meets the needs of 35-64 year olds (Greenfield et al. 2018; Adamson et al. 2018). The MoC focuses on community EIP services and does not include setting up specialised EIP inpatient beds (there are only a handful of such specialist units overseas). However, if hospitalised, patients would receive the same EIP interventions supported by in-reach from community EIP services. Unlike some other EIP service reforms, the $\mathrm{MoC}$ is relatively conservative and avoids cutting across traditional boundaries of Child \& Adolescent and Adult Mental Health Services (CAMHS/AMHS) or restricting itself to the youth population. Instead, it enhances the clinical resources within CAMHS and AMHS for those with early psychosis and promotes the smooth transition of EIP between the two.

\section{The introduction of EIP services in Ireland}

The EIP MoC is to be introduced in three stages. The first will be services for those with FEP, the second will be adding services for those at UHR for psychosis and the third will be the introduction of broader early detection strategies. With the first stage, three demonstration sites, based on the $\mathrm{MoC}$, have already been approved this year by the NCP (www.hse.ie), the South Lee service in Cork (Murray \& O'Connor, 2019), the EIP service in Meath and finally the EIP service in Sligo/Leitrim. DETECT still operates in south county Dublin and North Wicklow (www.detect.ie).

For the first stage of implementation, two variations of the EIP model are recommended by the MoC for adult services. The first is the Hub $\mathcal{E}$ Spoke model (Singh \& Fisher, 2005). This has a core EIP team at the Hub and EIP key workers distributed to each of the local community mental health teams (CMHTs), otherwise referred to as 'Spokes'. For example, it might have one hub and four spokes. This model augments and integrates with existing community mental health services in rural or smaller urban areas with a population of less than 200 000. The rationale for applying this 
model to less densely populated areas is that it will logistically operate better at a local level (more dispersed referrals over a wider catchment area) (Burbach et al. 2009; Fowler et al. 2009; Cheng et al. 2014). The second EIP model is the Stand-Alone model (Singh \& Fisher, 2005). This is a separate EIP team which operates relatively independently of existing CMHTs in large metropolitan areas with a population larger than 200000 (Power et al. 2007b). The rationale for having this model in densely populated metropolitan areas is for economies of scale, and to manage more frequent and complex referrals. Most of the evidence base for EIP services comes from Stand-alone services but there are good examples of Hub \& Spoke EIP services operating in rural areas (Burbach et al. 2009). The NCP's EIP MoC provides a very detailed description of these models and their relative benefits (HSE National Clinical Programme, 2019).

These EIP services are for those experiencing their first psychotic episode (more than 1 week of persistent psychotic symptoms). They provide a comprehensive and prompt MDT assessment followed by a range of biopsychosocial interventions over a 3 year period of follow-up to maximise the persons potential for a full recovery and minimise his/her risk of relapse, co-morbidities and chronicity. Each person will have a key worker and psychiatrist throughout their time with the service, overseeing care plans and access to interventions, such as Cognitive Behaviour Therapy for psychosis, Behaviour Family Therapy, Individual Placement and Support and treatment of co-morbidities such as drug abuse and mood disorders. The assessment and treatment options will be broad and varied, packaged in a way that caters for people's individual needs. It is essential to avoid limiting the service to a one size fits all 'set menu' of interventions. As people using the service will be predominately young people with their parents, the services and interventions will need to be youth and family friendly.

The second stage of the MoC implementation is for a clinical population at UHR of psychosis (Phillips et al. 2002). A large body of research over the past 25 years supports screening for those who might be at UHR of psychosis. Those with what is called an At Risk Mental State (ARMS) have approximately 30\% risk of developing psychosis in 3 years (Fusar-Poli et al. 2012). Clinical interventions can halve the risk of psychosis within the first year (van der Gaag et al. 2013). As the evidence base is limited to those aged 14-35, these new services are restricted to this age group at present. The MoC does not promote any particular preventative treatment over another but outlines a range of generic interventions to reduce the risk of psychosis, starting with psychological therapies (Schmidt et al. 2015). The MoC recommends that these new UHR services will operate as specialist tertiary assessment clinics, using standardised assessments such as the Comprehensive Assessment of At-Risk Mental States and the Structured Interview for Prodromal Symptoms (Fusar-Poli et al. 2016). Individual's clinical care and treatment will continue with local CMHTs, and for those identified with ARMS by the UHR assessment clinics, the recommendation is that they be followed up by the CMHTs for at least 2 years. If they become psychotic, their care and treatment will be promptly transferred to the EIP service for follow-up. Thereby, not only is the risk of psychosis minimised but, if they do still become psychotic, they will benefit from much earlier treatment (Valmaggia et al. 2015).

The third stage of the MoC implementation is to establish early detection strategies (Lloyd-Evans et al. 2011). This stage aims to reduce the long delays people with first episode psychosis experience in getting access to evidence based treatment. These delays (in areas without established early detection strategies) are on average 2 years of prodrome and 1 year of psychosis (Power et al. 2007a). Early detection strategies, such as raising awareness in the general public, educating referrers such as GPs and facilitating rapid access to assessments, have been shown to be effective in reducing these delays (Power et al. 2007a: Larsen et al. 2011; Lloyd-Evans et al. 2011). However, it is essential that EIP services (Stage 1) and UHR clinics (Stage 2) are already fully operational to receive these referrals as presentations caught earlier and at a younger age are often more difficult to detect, fluid in nature, challenge diagnostic categories and have high levels of co-morbidity.

No doubt, implementing the $\mathrm{MoC}$ will present considerable challenges, and the targets outlined in the $\mathrm{MoC}$ are ambitious. It will inevitably have its detractors (Pelosi, 2008). Ethical issues need to be kept in mind with UHR services, particularly if research driven (Lysaght et al. 2012). Controversy remains about the use of antipsychotic medication and the diagnostic specificity of the UHR concept (O'Connor, 2013; Yung \& Nelson, 2013). Implementation of EIP services will need to be sensitive to local service configurations and practice. They should be an integral part of local mental health services and ownership should rest with them. It will require consistent strong leadership, co-ordination and governance, as well as support from local services, service users and carers. Adequate funding, staffing, training and resources are vital. Particular efforts need to be made to avoid gaps in training/supervision and geographical variability in resourcing. Investment will need to be flexible to accommodate the wide variation in demand between rural, urban and metropolitan areas (Kelly et al. 2010; Kirkbride, 2015). Although these EIP services are likely 
to bring with them considerable downstream cost savings (McCrone et al. 2008; Park et al. 2016; Aceituno et al. 2019), these are unlikely to be seen in the first couple of years of operation.

When they are fully operational in Ireland, EIP services will be serving approximately 1500 new cases of psychosis (aged 14-65) a year. Two thirds will be under the age of 35 , and $15 \%$ will be under the age of 18 (Singh et al. 2003; Baldwin et al. 2005; Greenfield et al. 2018; Adamson et al. 2018). With 3 years follow-up, that will mean a total active case load in EIP services of over 4000 (with about 500 in CAMHS). With each EIP service covering a catchment area of 200 000, about 24 EIP services will be required (about 20 will be 'Hub \& Spoke'). In Stage 2, the addition of ARMS clinics is likely to identify several hundred adult/child ARMS cases annually, based on rates detected by overseas clinics (Ajnakina et al. 2017). Early Detection strategies in Stage 3 are likely to temporarily attract more undetected cases into EIP services until the numbers of new FEP cases are engaged earlier and ARMS interventions have reduced the incidence rates.

\section{Conclusion}

EIP in Ireland is at an exciting juncture. There is a very real prospect soon that patients and carers will be able to get access to and benefit from these new services. The HSE has committed to rolling these services out soon. Despite the struggles in recent years, Ireland's mental health services have considerable talent among its staff, trainees and institutions. To be successful, EIP will require their support and contributions. Research and academia also has potential to be a major contributor and driver for these service initiatives (Russell et al. 2019). It can explore new ways of delivering these services and fill the gaps in the existing evidence base. The research outlined in this special edition is an example of what can be done with limited resources. This marriage of service development and research evaluation brings a myriad of benefits to service provision, such as attracting grants, training, standardising measures, raising the quality of interventions and allowing comparisons between different models of service delivery.

Rolling out EIP services in Ireland will require considerable co-ordination, partnerships and collaboration. Establishing national networks (e.g. service development, training and research) will be crucial. Support for the role of NCP EIP Clinical Lead is pivotal. Working together, we can make EIP a success in Ireland and improve our services international reputation as well as delivering much needed interventions and better outcomes for patients and their families.
Are we there yet? Well, this MoC represents an important milestone. It provides a detailed and flexible road map. Based on this, three demonstration EIP teams are being set up this year and a 'stand-alone' EIP team is planned for next year. However, it will take another 3-5 years to fully implement the MoC across the whole country. We are not quite there yet - but the end is now in sight.

\section{Acknowledgements}

The EIP MoC is a joint initiative by the NCP and the $\mathrm{CPI}$. The author would like to acknowledge the important contributions from the NCP National Working Group, in particular the EIP National Clinical Lead, Dr Katherine Brown (and her successor Dr Karen O'Connor), Programme Manager, Rhona Jennings as well as the CPI's EIP CAG, in particular the Heads of Faculties and the CEO CPI, Miriam Silke. The author would also like to thank international experts (Pat McGorry, Jo Smith and David Shiers) for reviewing the EIP MoC. Ireland's Early Intervention for Psychosis Model of Care is available on www.hse.ie/ eng/about/who/cspd/ncps/mental-health/psychosis/ resources/. The CPI EIP CAG includes Dr Zetti Azvee, Dr Caragh Behan, Dr Katherine Brown, Prof. Mary Clarke, Dr Ciaran Corcoran, Prof. David Cotter, Dr Nina Devlin, Dr Maeve Doyle, Jennifer Hoblyn, Rhona Jennings, Dr John Lyne, Dr Catherine McDonough, Dr Mia McLaughlin, Dr Paul O'Connell, Dr Karen O'Connor, Dr Ray Paul, A/Prof. Paddy Power (chair), Dr Eric Roche, Dr Michael Scully, Ms Miriam Silke (CEO, CoPoI) and Ms Karen Smith. The NCP National Working Group includes Dr Katherine Brown (NCP EIP Clinical Lead), Rhona Jennings (EIP Programme Manager), Dr Edgar Lonergan, Ms Aine O'Reilly, Ms Mary Kelleher, Dr Brian Hallahan, Dr Nina Devlin, Dr Karen O'Connor, Dr Servaise Winkel, Mr Liam Hennessy, Mr Padraig O'Beirne, Prof. Mary Clarke and Prof. Aiden Corvin.

\section{Financial support}

No financial support was provided for this work.

\section{Conflicts of interest}

The author has no conflicts of interest to disclose.

\section{Ethical standards}

The author asserts that all procedures contributing to this work comply with the ethical standards of relevant national and institutional committee on human experimentation with the Helsinki Declaration of 1975 as revised in 2008 . 


\section{References}

Aceituno D, Vera N, Prina, AM, McCrone P (2019). Costeffectiveness of early intervention in psychosis: systematic review. British Journal of Psychiatry 215, 388-394.

Adamson V, Barras E, McConville S, Irikok C, Taylor K, Pitt S, Van Duyn R, Bennett S, Jackson L, Carroll J, Andrews M, Parker A, Wright C, Greathead K, Price D (2018). Implementing the access and waiting time standard for early intervention in psychosis in the United Kingdom: an evaluation of referrals and post-assessment outcomes over the first year of operation. Early Intervention in Psychiatry 12, 979-986.

Addington J (2012). International Early Psychosis Association (Editorial). Early Intervention in Psychiatry 6, 355-356.

Ajnakina O, Morgan C, Gayer-Anderson C, Oduola S, Bourque F, Bramley S, Williamson J, MacCabe JH, Dazzan P, Murray RM, David AS (2017). Only a small proportion of patients with first episode psychosis come via prodromal services: a retrospective survey of a large UK mental health programme. BMC Psychiatry 17, 308.

Baldwin P, Browne D, Scully PJ, Quinn JF, Morgan MG, Kinsella A, Owens JM, Russell V, O'Callaghan E, Waddington JL (2005). Epidemiology of first-episode psychosis: illustrating the challenges across diagnostic boundaries through the Cavan-Monaghan study at 8 years. Schizophrenia Bulletin 31, 624-638.

Burbach FR, Grinter DJ, Bues SE (2009). The Somerset team for early psychosis. Early Intervention in Psychiatry 3, 231-235.

Byrne P, Rosen A (editors) (2014). Early Intervention in Psychiatry: EI of Nearly Everything for Better Mental Health. Wiley Blackwell: Oxford, UK.

Cheng C, Dewa CS, Langill G, Fata M, Loong D (2014). Rural and remote early psychosis intervention services: the Gordian knot of early intervention. Early Intervention in Psychiatry 8, 396-405.

Cocchi A, Cavicchini A, Collavo M, Ghio L, Macchi S, Meneghelli A, Preti A (2015). Implementation and development of early intervention in psychosis services in Italy: a national survey promoted by the Associazione Italiana Interventi Precoci nelle Psicosi. Early Intervention in Psychiatry 12, 37-44

Correll CU, Galling B, Pawar A, Krivko A, Bonetto C, Ruggeri M, Craig TJ, Nordentoft M, Srihari VH, Guloksuz S, Hui CL (2018). Comparison of early intervention services vs treatment as usual for early-phase psychosis: a systematic review, meta-analysis, and meta-regression. JAMA Psychiatry 75, 555-565.

Csilag C, Nordentoft M, Mizuno M, McDaid D, Arango C, Smith J, Lora A, Verma S, di Fiandra T, Jones PB (2018). Early intervention in psychosis: from clinical intervention to health system implementation. Early Intervention in Psychiatry 12, 757-764.

Early Intervention for Psychosis Working Group 2012 (unpublished). An Implementation Plan for Early Intervention of Psychosis. Health Service Executive.
Edwards J, McGorry PD (2002). Implementing Early Intervention in Psychosis: A Guide to Establishing Early Psychosis Services. Dunitz: London.

Fowler D, Hodgekins J, Howells L, Millward M, Ivins A, Taylor G, Hackmann C, Hill K, Bishop N, Macmillan I (2009). Can targeted early intervention improve functional recovery in psychosis? A historical control evaluation of the effectiveness of different models of early intervention service provision in Norfolk 1998-2007. Early Intervention in Psychiatry 3, 282-288.

Fusar-Poli P, Bonoldi I, Yung AR, Borgwardt S, Kempton MJ, Valmaggia L, Barale F, Caverzasi E, McGuire $P$ (2012). Predicting psychosis: a meta-analysis of transition outcomes in individuals at high clinical risk. Archives of General Psychiatry 69, 220-229.

Fusar-Poli P, Cappucciati M, Rutigliano G, Lee TY, Beverly Q, Bonoldi I, Lelli J, Kaar SJ, Gago E, Rocchetti M, Patel R, Bhavsar V, Tognin S, Badger S, Calem M, Lim K, Kwon JS, Perez J, McGuire P (2016). Towards a standard psychometric diagnostic interview for subjects at ultra-high risk of psychosis: CAARMS versus SIPS. Psychiatry 2016, 7146341.

Fusar-Poli P, McGorry PD, Kane JM (2017). Improving outcomes of first-episode psychosis: an overview. World Psychiatry 16, 251-265.

Goldner-Vukov M, Cupina DD, Moore LJ, Baba-Milkic N, Milovanovic S (2007). Early intervention in first episode psychosis: hope for a better future. Srpski arhiv za celokupno lekarstvo 135, 672.

Greenfield P, Joshi S, Christian S, Lekkos P, Gregorowicz A, Fisher HL, Johnson $S$ (2018). First episode psychosis in the over 35s: is there a role for early intervention? Early Intervention in Psychiatry 12, 348-354.

HSE National Clinical Programme (2019). HSE National Clinical Programme for Early Intervention in Psychosis Model of Care. HSE Publications, ISBN: 978-1-78602-128-1 (https://www.hse.ie/eng/about/who/cspd/ncps/mentalhealth/psychosis/resources/).

Kelly BD, O'Callaghan E, Waddington J L, Feeney L, Browne S, Scully PJ, Clarke M, Quinn JF, McTigue O, Morgan MG, Kinsella A, Larkin C (2010). Schizophrenia and the city: a review of literature and prospective study of psychosis and urbanicity in Ireland. Schizophrenia Research 116, 75-89.

Kirkbride JB (2015). Epidemiology on demand: populationbased approaches to mental health service commissioning. British Journal of Psychiatry Bulletin 39, 242-247.

Lalevic G, Scriven M, O'Brien S(2019). Early intervention in psychosis in the North Lee Mental Health Services programme: a 5-year review. Irish Journal of Psychological Medicine 36, 271-277.

Larsen TK, Melle I, Auestad B, Haahr U, Joa I, Johannessen JO, Opjordsmoen S, Rund BR, Rossberg JI, Simonsen E, Vaglum P, Friis S, McGlashan T (2011). Early detection of psychosis: positive effects on 5-year outcome. Psychological Medicine 41, 1461-1469. 
Lloyd-Evans B, Crosby M, Stockton S, Pilling S, Hobbs L, Hinton M, Johnson S (2011). Initiatives to shorten duration of untreated psychosis: systematic review. British Journal of Psychiatry 198, 256-263.

Lysaght T, Capps B, Subramaniam M, Chong SA (2012). Translational and clinical research in Singapore: ethical issues in a longitudinal study of the prodromal phase of schizophrenia. Early Intervention in Psychiatry 6, 3-10.

McCrone P, Dhanasiri S, Patel A, Knapp M, Lawton-Smith S (2008). Paying the Price: The Cost of Mental Health Care in England to 2026. London: The King's Fund.

McDaid D, Park AL, Iemmi V, Adelaja B, Knapp M (2016). Growth in the Use of Early Intervention for Psychosis Services: An Opportunity to Promote Recovery Amid Concerns on Health Care Sustainability. Personal Social Services Research Unit, London School of Economics and Political Science: London, UK.

McGorry PD (2015). Early intervention in psychosis: obvious, effective, overdue. Journal of Nervous and Mental Disease 203, 310-318.

McGorry PD, Killackey E, Yung A (2008). Early intervention in psychosis: concepts, evidence and future directions. World Psychiatry 7, 148-156.

McGorry PD, Mei C (2018). Early intervention in youth mental health: progress and future directions. Evidence Based Mental Health, 21:182-184

Murray N, O'Connor K (2019). Retrospective study of a first-episode psychosis service embedded within a home-based treatment team. Irish Journal of Psychological Medicine 36, 265-269.

National Institute for Health and Clinical Excellence (NICE) (2013). Psychosis and Schizophrenia in Children and Young People. Recognition and Management: Clinical Guidelines (CG155). RCPsych Publications: London.

National Institute for Health and Clinical Excellence (NICE) (2014) Psychosis and Schizophrenia in Adults: Prevention and Management, National Clinical Practice Guidelines (CG178). NICE RCPsych Publications: London.

Niendam TA, Sardo A, Savill M, Patel P, Xing G, Loewy RL, Dewa CS, Meinikow J (2019). The rise of early psychosis care in California: an overview of community and university-based services. Psychiatric Services 70, 480-487.

Nkire N, Sardinha S, Nwosu B, McDonough CM, De Coteau PA, Duffy I, Waddington JL, Russell V (2015). Evaluation of knowledge and attitudes among primary care physicians in Cavan-Monaghan as 'gatekeepers-inwaiting' for the introduction of Carepath for Overcoming Psychosis Early (COPE). Early Intervention in Psychiatry 9, 141-150.

O'Connor K (2013). Research in young people at ultra-high risk for psychosis: a review of the current evidence. Irish Journal of Psychological Medicine 30, 77-89.

Omer S, Behan C, Waddington JL, O'Callaghan E (2010). Early intervention in psychosis: service models worldwide and the Irish experience. Irish Journal of Psychological Medicine 27, 210-214.

Park AL, McCrone P, Knapp M (2016). Early intervention for first episode psychosis: broadening the scope of economic estimates. Early Intervention in Psychiatry 10, 144-151.

Pelosi A (2008). Is early intervention in the major psychiatric disorders justified? British Medical Journal 337, a710.

Phillips LJ, Leicester SB, O'Dwyer LE, Francey SM, Koutsogiannis J, Abdel-Baki A, Kelly D, Jones S, Vay C, Yung AR, McGorry PD (2002). The PACE Clinic: identification and management of young people at 'ultra' high risk of psychosis. Journal of Psychiatric Practice 8 , 255-269.

Power P, Iacoponi E, Reynolds N, Fisher H, Russell M, Garety P, McGuire PK, Craig T. (2007a). The Lambeth Early Onset Crisis Assessment Team Study: general practitioner education and access to an early detection team in first-episode psychosis. British Journal of Psychiatry 51, s133-s139.

Power P, McGuire P, Iacoponi E, Garety P, Morris E, Valmaggia L, Grafton D, Craig T (2007b). Lambeth Early Onset (LEO) and Outreach \& Support in South London (OASIS) service. Early Intervention in Psychiatry 1, 97-103.

Russell V, Nkire N, Kingston T, Waddington JL (2019). Forging successful partnerships in psychosis research: lessons from the Cavan-Monaghan First Episode Psychosis Study. Irish Journal of Psychological Medicine.

Schmidt SJ, Schultze-Lutter F, Schimmelmann BG, Maric NP, Salokangas RKR, Riecher-Rössler A, van der Gaag M, Meneghelli A, Nordentoft M, Marshall M, Morrison A (2015). EPA guidance on the early intervention in clinical high risk states of psychoses. European Psychiatry 30, 388-404.

Singh S, Fisher HL (2005). Early intervention in psychosis: obstacles and opportunities. Advances in Psychiatric Treatment 11, 71-78.

Singh S, Wright C, Joyce E, Barnes T, Burns TS (2003). Developing early intervention services in the NHS: a survey to guide workforce and training needs. Psychiatric Bulletin 27, 254-258.

Valmaggia LR., Byrne M, Day F, Broome MR, Johns L, Howes O, Power P, Badger S, Fusar-Poli P, McGuire PK (2015). Duration of untreated psychosis and need for admission in patients who engage in the prodromal phase. British Journal of Psychiatry 207, 130-134.

van der Gaag M, Smit F, Bechdolf A, French P, Linszen DH, Yung AR, McGorry P, Cuijpers P (2013). Preventing a first episode of psychosis: meta-analysis of randomized controlled prevention trials of 12 month and longer-term follow-ups. Schizophrenia Research 149, 56-62.

Yung A, Nelson B (2013). The Ultra-High Risk concept: a review. Canadian Journal of Psychiatry, Revue Canadienne de Psychiatrie 58, 5-12. 